Research Article

\title{
Development of a New Cold Metal Transfer Arc Additive Die Manufacturing Process
}

\author{
An Zhang, ${ }^{1}$ Yanfeng Xing $\mathbb{D}^{1}{ }^{1}$ Fuyong Yang, ${ }^{1}$ Xiaobing Zhang, ${ }^{1}$ Hongze Wang, ${ }^{2}$ \\ and Tiejun $\mathbf{Y u}^{3}$ \\ ${ }^{1}$ School of Mechanical and Automotive Engineering, Shanghai University of Engineering Science, Shanghai 201620, China \\ ${ }^{2}$ School of Materials Science and Engineering, Shanghai Jiao Tong University, Shanghai 200240, China \\ ${ }^{3}$ Shanghai Heda Auto Parts Limited Company, Shanghai 201799, China
}

Correspondence should be addressed to Yanfeng Xing; smsmsues@163.com

Received 4 July 2021; Revised 7 September 2021; Accepted 22 October 2021; Published 5 November 2021

Academic Editor: Dimitrios E. Manolakos

Copyright (c) 2021 An Zhang et al. This is an open access article distributed under the Creative Commons Attribution License, which permits unrestricted use, distribution, and reproduction in any medium, provided the original work is properly cited.

Due to its high efficiency, cold metal transfer (CMT) arc additive manufacturing presents considerable potential in the aluminium alloy additive manufacturing industry. However, during CMT arc additive manufacturing, the surrounding air environment promotes the lateral flow of liquid aluminium and the instability of the molten pool, reduces the surface quality and material utilisation of deposition walls, and causes internal hydrogen pores and coarse columnar grains, which negatively affect the structure and mechanical properties of the deposition walls. This study developed a CMT arc additive die manufacturing process to control the substrate material and deposition path to improve the physical properties of the deposition wall. The experimental results indicated that the copper plates can affect molten pool flow and material formation in the additive process, minimise hydrogen pores, and refine columnar grains. The porosity dropped from $2.03 \%$ to $0.93 \%$, and the average grain size decreased from $16.2 \pm 1.4$ to $13.6 \pm 1.3 \mu \mathrm{m}$, thereby enhancing the structure and mechanical properties of the deposition wall to attain standard additive manufacturing products.

\section{Introduction}

Arc additives present a wide range of applications in the engineering manufacturing. It is common to use the arc additive manufacturing technology to prepare nickel-aluminium intermetallic compounds or nickel-based alloys $[1,2]$. Productive additive manufacturing processes are pursued by manufacturing industries [3]. Process monitoring and inspection can improve the productivity of additive manufacturing [4]. CMT arc additive manufacturing is high-efficiency industrial technology. However, low deposition accuracy and structural properties limit the development of this technology. In general, pore defects are considered the main problem of aluminium alloy arc additive manufacturing [5]. Aluminium alloy pores mainly result from hydrogen, and the correlation between the number of pores and hydrogen-containing molecules is approximately linear [6]. Quantitative statistical analysis of the shape and number of pores in aluminium alloys can facilitate the understanding of the influence of deposition parameters on the alloys [7]. The deposition walls hammered between layers are believed to exhibit highly refined grains [8]. The middle area of the deposition wall mainly constitutes uniform equiaxed grains along the generation direction [9]. When the number of deposition layers increases, due to thermal cycling, columnar grains increase and grow along the generation direction [10].

A study found that the position of a welding wire is an important factor determining the effect of transition between a droplet and molten pool, for a rectangular deposition wall, and the zero-deflection welding wire presents high accurate feeding and withdrawal movements, which are beneficial for deposition [11]. Reciprocating deposition motion can be used to obtain relatively thicker walls [12]. The alternating deposition direction of welding wires is conducive to the construction of a regular deposition wall 
and substantially improves the uniformity and stability of deposition walls [13]. When a new layer of aluminium alloy is deposited, its adjacent layer is remelted and severely deformed [14]. A part of the deposition wall exhibits overlapping areas in the lateral direction and has a multilayer structure along the deposition velocity direction [15]. A correlation exists between the microstructure and geometric factors of aluminium alloys [16]. The strength is higher in the vertical direction than in the horizontal direction, and the elongation is almost the same [17].

Studies have reported that the arc energy influences the microstructure and mechanical properties [18]. With an increase in temperature, the internal porosity and grain size of the aluminium alloy increase, and its tensile and yield strengths gradually decrease [19]. The actively cooled deposition wall has lower surface roughness than the freely cooled deposition wall [20]. Through the heat treatment, materials with high hardness and ductility can be obtained [21]. In arc additive manufacturing, the Lorentz force, temperature gradient shear stress, plasma shear stress, and heat flow distribution on the molten pool surface are different from those in conventional additive manufacturing [22]. The full-time recording of the deposition current, voltage, material thermal cycle, and high speed arc images can be used to understand the mechanical behaviour of the molten pool [23].

The insertion process of particles materials affects the structure and organisation of the deposited walls [24]. Nanoparticles can control the solidification behaviour of high-strength aluminium alloys [25], and with nanomaterials, the ultimate tensile strength and elongation of the wall increase [26]. The structure optimisation and organisation homogenisation of the deposition wall of arc additive manufacturing can be achieved in the subsequent process [27]. Arc additive manufacturing must overcome the key problem of strengthening the structural organisation and mechanical properties of the deposition wall [28]. In general, the contact interface layer between the aluminium alloy and dissimilar metals includes a continuous layer and discontinuous layer [29]. No defects are present near the boundary between the two metals [30]. Therefore, this study developed a CMT arc additive die-casting manufacturing process to overcome the disadvantages of traditional arc additive manufacturing in deposition accuracy and structural organisation performance and achieved an additive structure that meets industrial manufacturing standards.

\section{Experimental Procedure}

2.1. Experimental Method. CMT arc additive die manufacturing was executed on an integrated deposition platform. The 7075 aluminium alloy substrates were fixed at the top of the deposition platform by using positioning fixtures, and the T2 copper plates were fixed on both the sides of the deposition path. Manufacturing was conducted with an ER4043 aluminium-silicon welding wire, and the argon gas protection treatment was simultaneously performed. Table 1 presents the standard chemical composition
TABLE 1: Composition of the 7075 aluminium alloy substrate, T2 copper plate, and ER4043 welding wire (\%).

\begin{tabular}{lcccccccc}
\hline & $\mathrm{Al}$ & $\mathrm{Si}$ & $\mathrm{Fe}$ & $\mathrm{Cu}$ & $\mathrm{Mn}$ & $\mathrm{Mg}$ & $\mathrm{Cr}$ & $\mathrm{Zn}$ \\
\hline 7075 & $\mathrm{Bal}$ & 0.60 & 0.70 & 0.25 & 0.12 & 1.10 & 0.01 & 0.20 \\
ER4043 & $\mathrm{Bal}$ & 5.60 & 0.80 & 0.30 & 0.05 & 0.05 & 0.01 & 0.10 \\
T2 & - & - & 0.01 & $\mathrm{Bal}$ & 0.01 & - & - & - \\
\hline
\end{tabular}

of the 7075 aluminium alloy substrate, copper plate, and welding wire.

Figure 1 shows the CMT arc additive die manufacturing device. The KUKA robot was used to assist CMT deposition to control the movement path and speed of the welding gun. The wire feeding system was used to adjust the wire feeding speed to control the deposition speed. The initial distance between the welding wire and aluminium alloy substrate remained constant, and the welding torch was positioned above the substrate during the movement and was used to feed the molten welding wire. Under the fixed path of the aluminium alloy substrate and copper plates, the welding torch layer-by-layer accumulated the aluminium-silicon alloy and finally formed the deposition wall.

The copper plates were superimposed with an overlay fixture to keep the height of the plates consistent with the molten pool before deposition. Before each deposition, an infrared thermometer was used to measure the temperature of the copper plates to keep it at about $20^{\circ} \mathrm{C}$, which can accelerate the heat dissipation of the molten pool during deposition. After each deposition, cold air was used to cool the deposition wall to minimise the heat input and thermal deformation. Deposition was conducted on a platform without path restriction and copper plates restriction path. The deposition length without path restriction was approximately $140 \mathrm{~mm}$ and 28 layers in the $X$ and $Z$ directions, respectively, and that with the copper plates restriction path was approximately $140 \mathrm{~mm}$ and 22 layers in the $X$ and $Z$ directions, respectively, as shown in Figure 2.

After the completion of deposition, the structural dimensions of the front and side of the CMT deposition wall were observed, and their geometric differences were compared. The pore size and distribution inside the deposition wall were observed using a CNC wire cutting machine, and the microstructure of the deposition wall was analysed using the Leica DM4M metallurgical microscope. Subsequently, the deposition wall samples of the transverse and longitudinal sections were selected for mechanical tensile tests. Finally, scanning electron microscopy (SEM) was used to observe the microstructure of the tensile fracture crack and analyse its fracture mechanism, as shown in Figure 3.

2.2. Layer Width and Layer Thickness. The layer width and thickness of the deposition wall served as the standards of additive manufacturing efficiency. Under the same deposition conditions, the layer width value was smaller when it was not lower than the preset width, and the layer thickness value was larger when it was not higher than the preset height. 


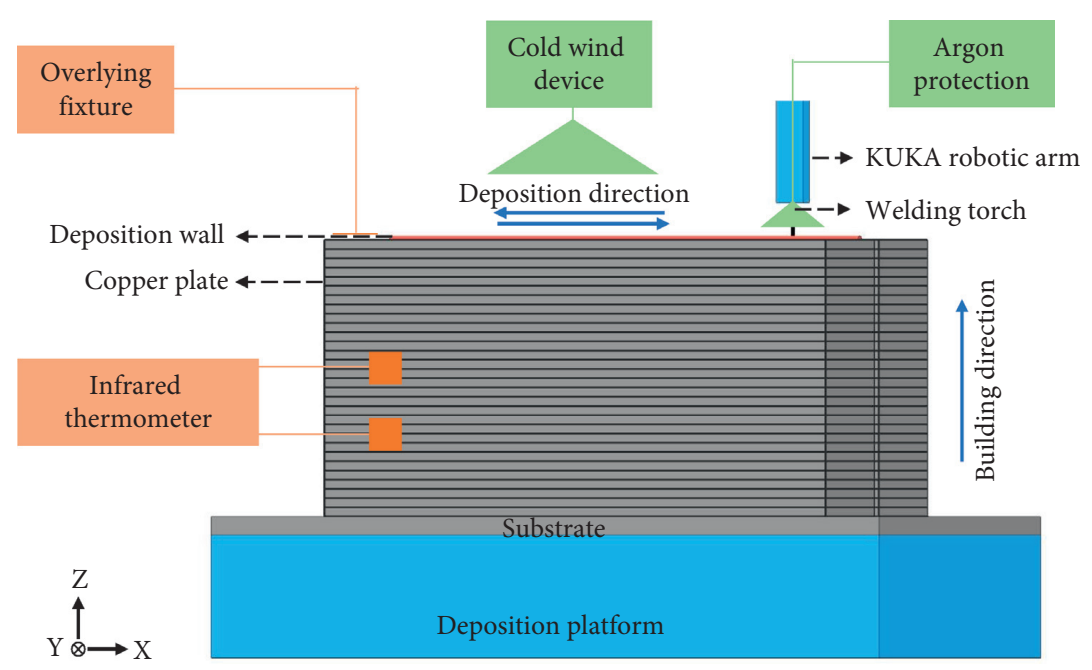

Figure 1: CMT arc additive die manufacturing device.

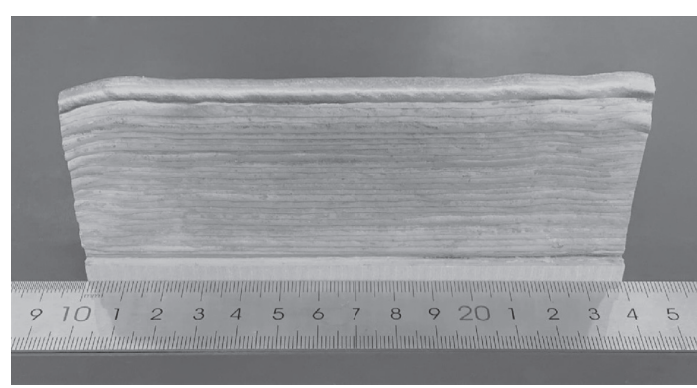

(a)

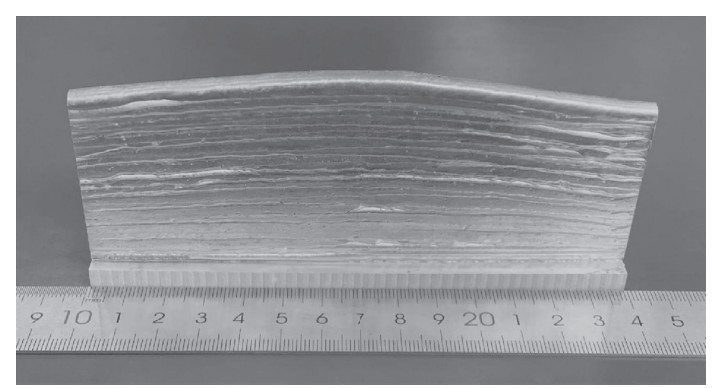

(b)

FIGURE 2: Shape and size of the deposition wall (a) without path restriction and (b) with the copper plates constrained path.

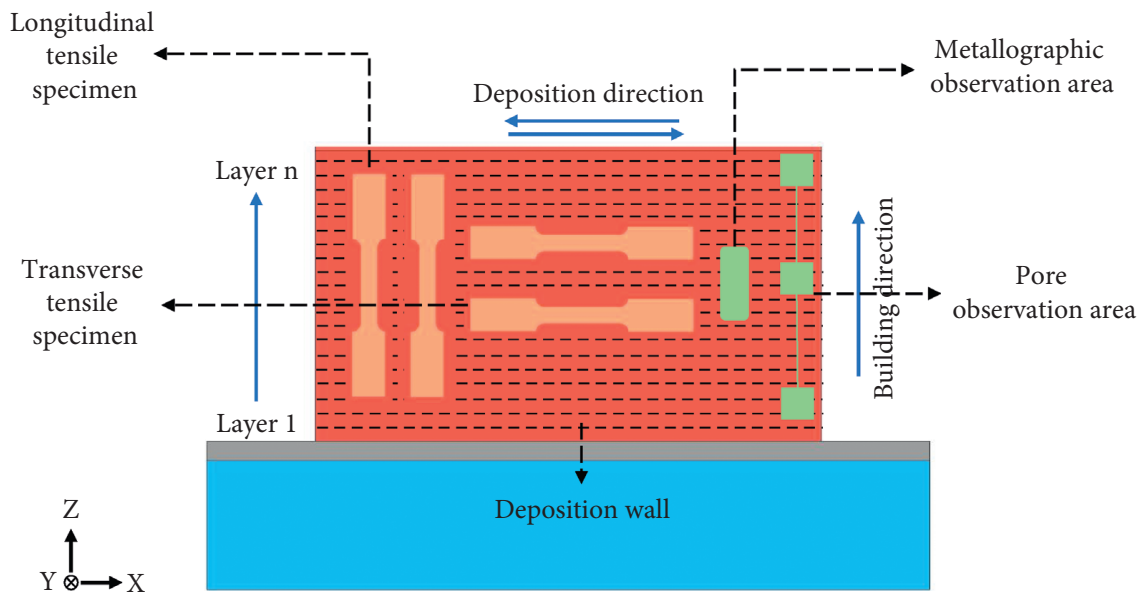

FIgURE 3: Test area of the deposition wall.

For the deposition wall without any path constraint, in the 1-6th layers of the deposition wall, the molten pool dynamically flowed to both the sides because air was in contact with both sides of the molten pool, and the flow velocity of the molten pool on the two sides is greater than that in the middle. The layer width of the deposition wall in the direction of interlayer accumulation became wider layer by layer, indicating a changing trend. Corresponding to the layer width, because the volume of each layer of the deposition wall was constant, the layer thickness of the 
deposition wall in the direction of interlayer accumulation tended to decrease layer by layer. In the 7-28th layers of the deposition wall, because the trend of the dynamic flow of the molten pool in the middle and on both sides attained a dynamic balance, the layer width change trend of the deposition wall in the direction of the interlayer accumulation remained constant. Corresponding to the layer width, because the volume of each layer of the deposition wall remained unchanged, the trend of layer thickness change of the deposition wall in the direction of interlayer accumulation was constant, as shown in Figure 4.

In CMT arc additive die-casting manufacturing, for the deposition wall with the copper plates constrained path, in the 1-22nd layers of the deposition wall, the tendency of the molten pool to dynamically flow to both the sides was restricted and dynamic backflow occurred in the middle because of the surface constraint. Thus, the molten pool concentrated in the set space area, and the trend of the layer width change of the deposition wall in the direction of interlayer accumulation was unchanged. Corresponding to the layer width, because the volume of each layer of the deposition wall was constant, the trend of layer thickness change of the deposition wall in the direction of interlayer accumulation remained unchanged, as shown in Figure 5.

2.3. Side Flatness and Top Surface Volatility. The side surface flatness and top surface volatility of the deposited wall were the main standards for determining the surface quality and material utilisation of additive manufacturing. Under the same deposition conditions, the side surface flatness was close to the zero mark, the top surface volatility was smooth, and the surface quality and material utilisation of the deposition wall were high. According to the experiments, the calculation formulas for side flatness $P$ and top surface volatility $F$ are as follows:

$$
\begin{aligned}
& P=\frac{Y-Y_{0}}{Y_{0}}, \\
& F=Z+Z_{0},
\end{aligned}
$$

where $Y$ is the deposition width of the deposition wall, $Y_{0}$ is the average deposition width of the deposition wall, $Z$ is the height of the deposition wall above the substrate, and $Z_{0}$ is the penetration depth of the deposition wall below the substrate.

For the deposition wall without path constraints, the deposition wall distance in the direction of the deposition velocity was $142.5 \mathrm{~mm}$. Because of the alternating contact between the solid and liquid phases of the layers, the side of the deposition wall was flat in the area away from the contact line, and protrusions and depressions occurred in the area near the contact line. The side surface flatness of the deposition wall was poor, the value of $\mathrm{P}$ was $11 \%$, and the distribution law of the side flatness of the deposition wall in the interlayer accumulation direction was discrete distribution. Because the arc circulates at both ends during deposition, fluctuations at the top surface of the deposition wall were low at both ends, and the middle area fluctuated irregularly and slightly. The top surface fluctuation distribution of the deposition wall in the direction of the deposition velocity was the arc distribution, and the highest point was $54 \mathrm{~mm}$, as shown in Figure 6.

In CMT arc additive die-casting manufacturing, for the deposition wall with the copper plates constrained path, the deposition wall distance in the direction of the deposition velocity was $142.5 \mathrm{~mm}$. Because of the surface constraints, the protrusions of the deposition wall in the area around the contact line were suppressed, and the side surface flatness of the deposition wall was relatively better. But there are still some depressions in the area around the contact line. First, the high temperature molten pool cools and shrinks after touching the surface of the copper plate. Second, the deviation of the position of the copper plate causes uneven solidification of the molten pool. The value of $\mathrm{F}$ was $3 \%$, and the distribution law of the side surface flatness of the deposition wall in the deposition velocity direction was uniform. Because of the copper plates' restriction and heat accumulation in the middle, the middle area was subjected to a high rate of thermal expansion, and a high bump was obtained. The top surface volatility was lower at both the ends and higher in the middle, and the top volatility distribution of the deposition wall in the direction of interlayer accumulation is the arc distribution. The highest point is $57 \mathrm{~mm}$, as shown in Figure 7.

Under the same experimental conditions, for the deposition wall without the path constraints, the design of its size is mainly based on the adjustment of deposition parameters, and the adjustment interval of deposition parameters is narrow, which seriously affected the deposition quality and efficiency of the wall. Satisfying the requirements of industrial design is difficult, and under the general experimental conditions, the deposition wall surface must be processed from the addition to subtraction, which greatly hampers material utilisation. For the deposition wall with the copper plates constrained path, a fixed deposition path and deposition interval can be set before deposition. The deposition wall can be deposited with a specific size according to the copper plates position, which considerably improves its deposition efficiency. Moreover, it generally does not require the surface cutting or slight surface grinding treatment, which substantially improves the material utilisation degree.

\section{Results and Discussion}

3.1. Pore Defect Analysis. For the deposition wall without the path constraint, the pore size and distribution on its cross section are shown in Figures 8(a)-8(c). During deposition, the bottom of the molten pool is in contact with the upper layer of the weld, and other parts are in direct contact with the air. The average cooling rate of the molten pool is relatively low, and the air present in the molten pool cannot rapidly escape from the deposition wall before it solidifies, which leads to the formation of more pores in the deposition wall. In this state, the average porosity of the deposition wall is $2.03 \%$, and the maximum pore diameter is $1.20 \mathrm{~mm}$, which 

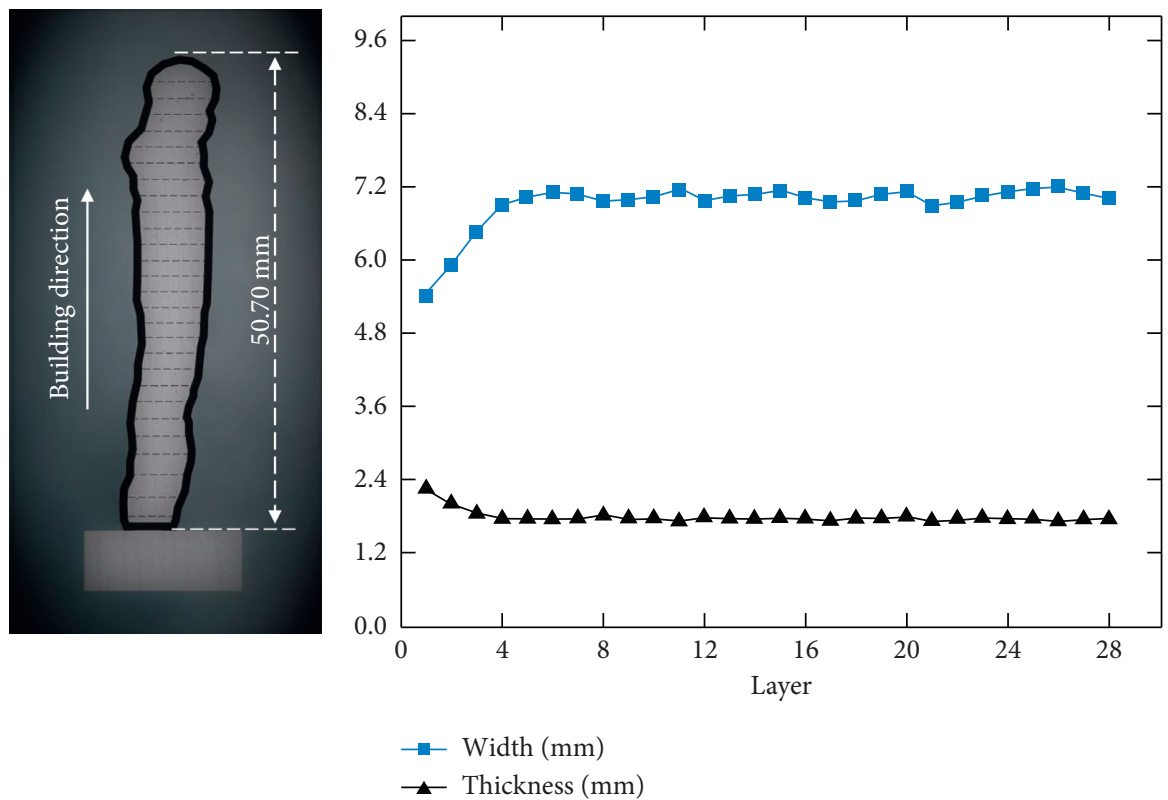

FIGURE 4: Layer width and thickness of the deposition wall without the path constraint.
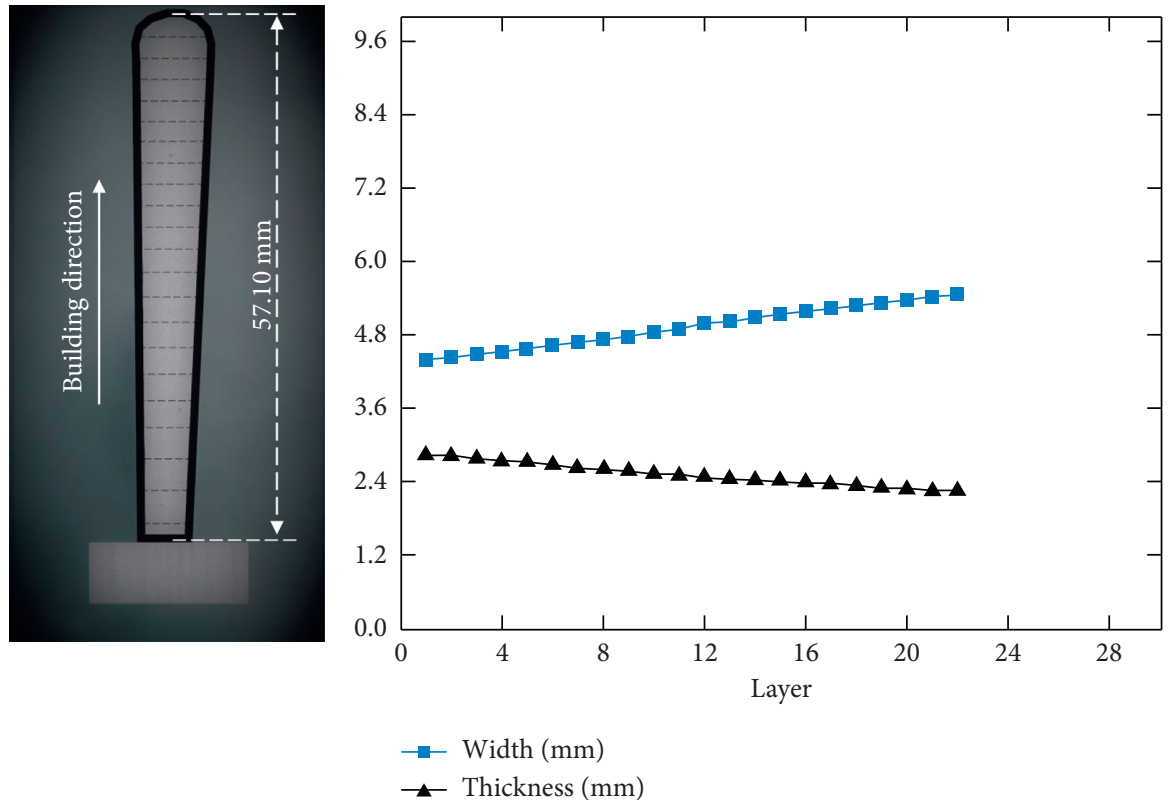

Figure 5: Layer width and thickness of the deposition wall with the copper plates constrained path.

seriously affects the mechanical properties of the deposition wall.

For the deposition wall with the copper plates constrained path, the pore size and distribution on the cross section of the wall are shown in Figures $8(\mathrm{~d})-8(\mathrm{f})$. During deposition, the bottom and top of the molten pool are in contact with the upper layer of the weld and air, respectively, and other parts are in direct contact with the copper plates on both the sides. The average cooling rate of the molten pool is relatively high, which promotes the air present as pores in the molten pool to rapidly escape from the deposition wall before the molten pool solidifies, leading to the reduction in the number of pores in the deposition wall. In this state, the average porosity of the deposition wall is $0.93 \%$, and the maximum pore diameter is $0.55 \mathrm{~mm}$, as the average density of the deposition wall increases, it has better compactness, which improves the mechanical properties of the deposition wall.

3.2. Heat-Transfer Model. The heat-transfer method and heat-transfer rate of the molten pool during the additive manufacturing of the deposition wall are the main factors determining molten pool temperature [31]. Heat 


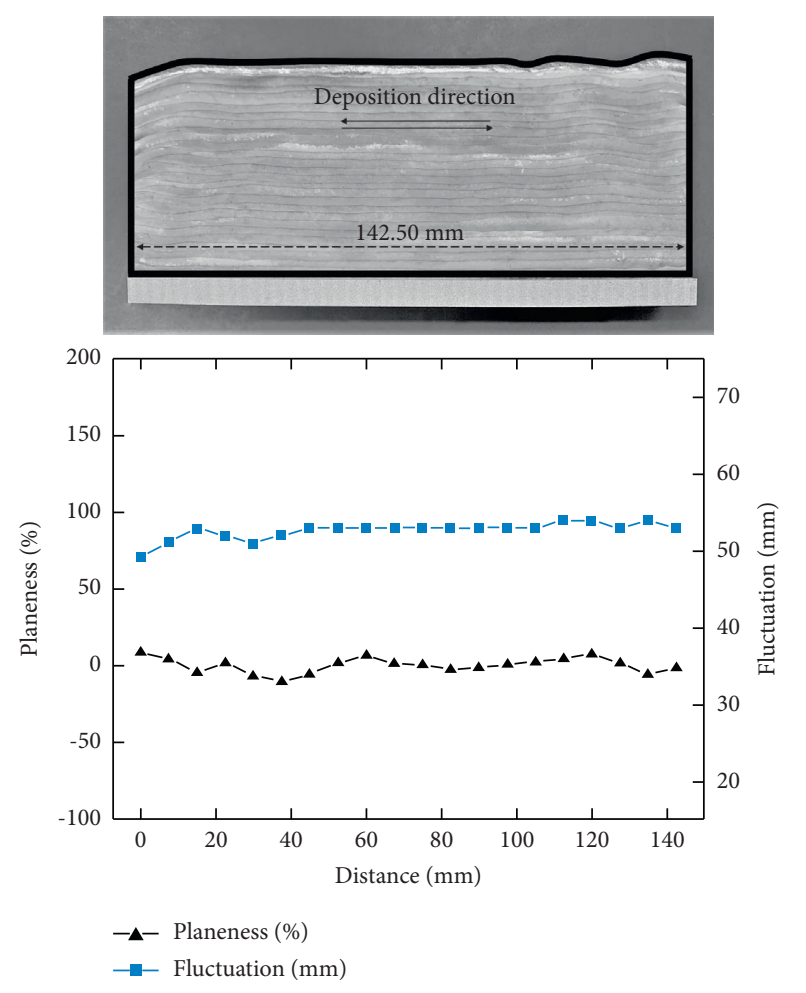

FIGURE 6: Side flatness and top surface volatility of the deposition wall without path constraint.

conduction, heat convection, and heat radiation are generally considered the methods of heat transfer of the molten pool during deposition, and the heat flux is the factor determining the heat-transfer rate of the molten pool [32].

For deposition wall without the path constraints, during deposition, the bottom of the molten pool is in contact with the deposition weld of the upper layer; the front, back, and top of the molten pool are in contact with the air; and the two sides of the molten pool and air form an air-interface heattransfer system. During deposition, the heat-transfer methods of the molten pool mainly are heat convection and radiation; heat conduction can be ignored, and the heat flux density of the molten pool can be expressed as follows:

$$
q=\frac{\lambda\left(T_{1}-T_{2}\right)}{\Delta L}+\frac{f \beta g\left(T_{1}-T_{2}\right) \Delta L^{3}}{v^{2}}+k \sigma \varepsilon_{1} T_{1}^{4}
$$

where $\lambda$ is the thermal conductivity of the air, $T_{1}$ is the side temperature of the molten pool, $T_{2}$ is the air temperature, $\Delta L$ is the characteristic scale of the air, $f$ is the convective heattransfer index, $\beta$ is the coefficient of air expansion, $g$ is the acceleration of gravity, $v$ is the air movement viscosity, $k$ is the radiation heat-transfer index, $\sigma$ is the Stephen-Boltzmann constant, and $\varepsilon_{1}$ is the emissivity of the deposition wall surface.

For the deposition wall with the copper plates constrained path, during deposition, the bottom of the molten pool is in contact with the deposition weld of the upper layer; the front, back, and top of the molten pool are in contact with the air; and the two sides of the molten pool and copper plates form an air-gap-interface heat-transfer system.
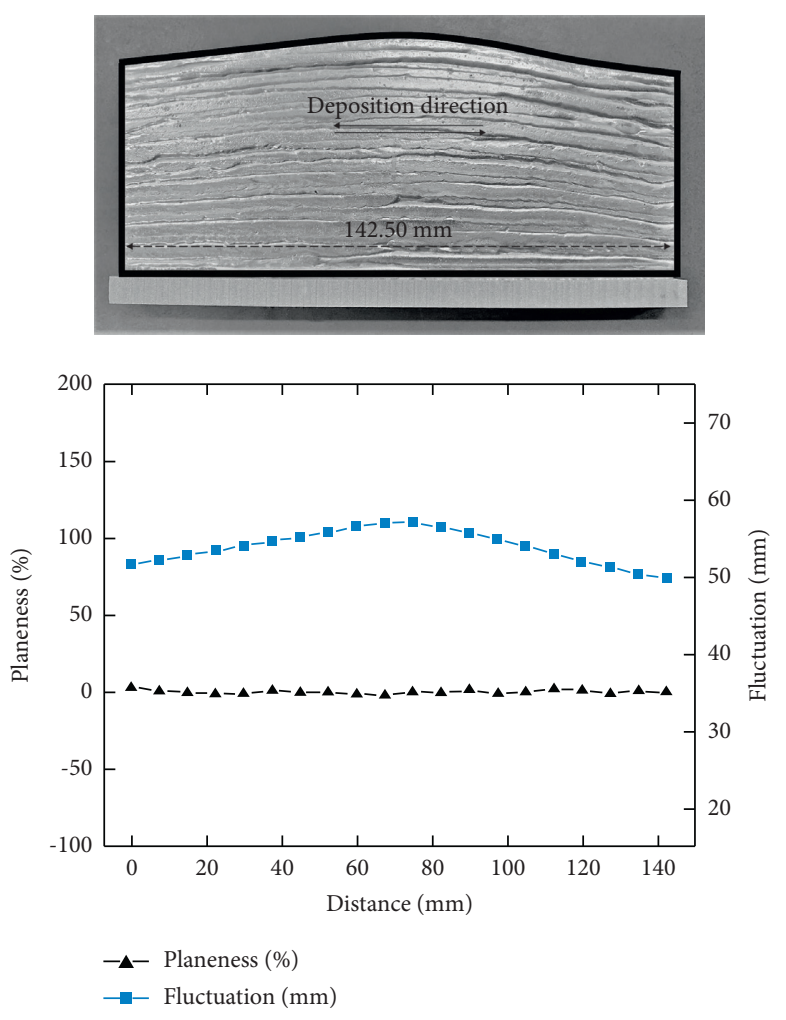

Figure 7: Side flatness and top surface volatility of the deposition wall with the copper plates constrained path.

During deposition, the heat-transfer methods of the molten pool mainly are heat conduction and radiation; heat convection can be ignored, and the heat flux density of the molten pool can be expressed as follows:

$$
q=\frac{\lambda\left(T_{1}-T_{2}\right)}{\alpha L\left(T-T_{0}\right)}+\frac{f \alpha^{3} \beta g L^{3}\left(T_{1}-T_{2}\right)\left(T-T_{0}\right)^{3}}{\nu^{2}}+\frac{k \sigma\left(T_{1}^{4}-T_{2}^{4}\right)}{1 / \varepsilon_{1}+1 / \varepsilon_{2}-1},
$$

where $\lambda$ is the thermal conductivity of the air, $T_{1}$ is the temperature of the side of the molten pool, $T_{2}$ is the temperature of the copper plates, $\alpha$ is the linear expansion coefficient of the deposition wall, $L$ is the width of the copper plates, $T$ is the initial temperature of the deposition wall, $T_{0}$ is the cooled temperature of the deposition wall, $f$ is the convective heat-transfer index, $\beta$ is the expansion coefficient of air, $g$ is the acceleration of gravity, $v$ is the air kinematic viscosity, $k$ is the radiation heat-transfer index, $\sigma$ is the Stephen-Boltzmann constant, $\varepsilon_{1}$ is the emissivity of the deposition wall surface, and $\varepsilon_{2}$ is the emissivity of the copper plates surface.

For the deposition wall without path restriction, during deposition, the heat-transfer modes of the molten pool mainly are convection and radiation; the heat-transfer density of the molten pool is small, and the cooling rate is slow. When the deviation between the transient thermal result and actual measured temperature is within $10 \%$, then according to the transient thermal analysis, the temperature field gradient distribution of the deposition wall in the first layer is shown in Figure 9(a). At the end of the wall when the 


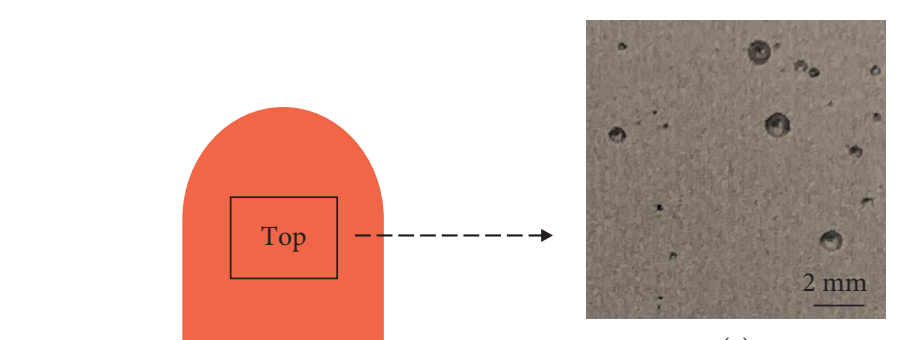

(a)

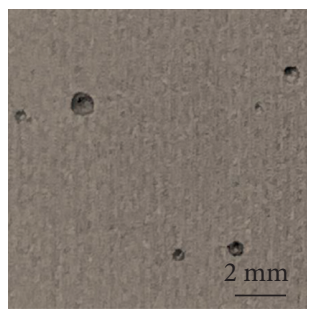

(b)

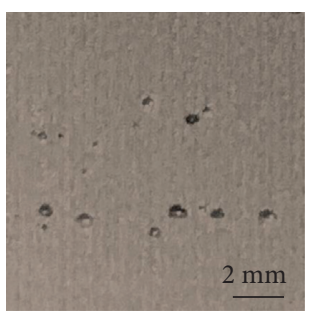

(c)

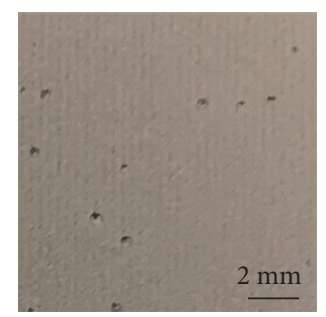

(d)

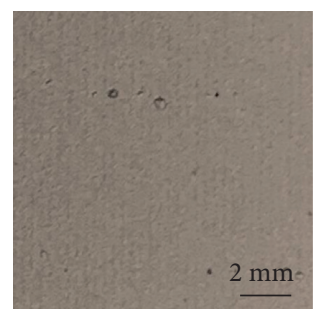

(e)

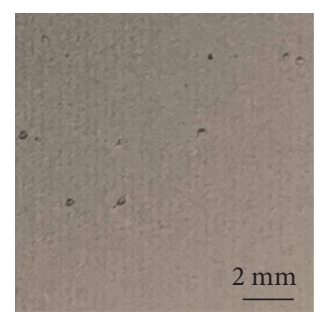

(f)

FIGURE 8: Pore size and distribution on the cross section of the deposition wall: (a)-(c) without the path constraint and (d)-(f) with the copper plates constrained path.

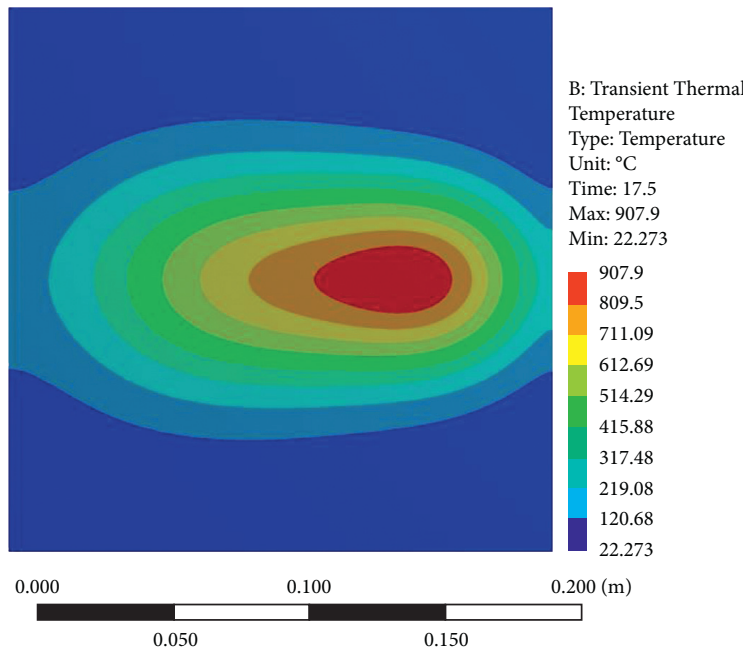

(a)

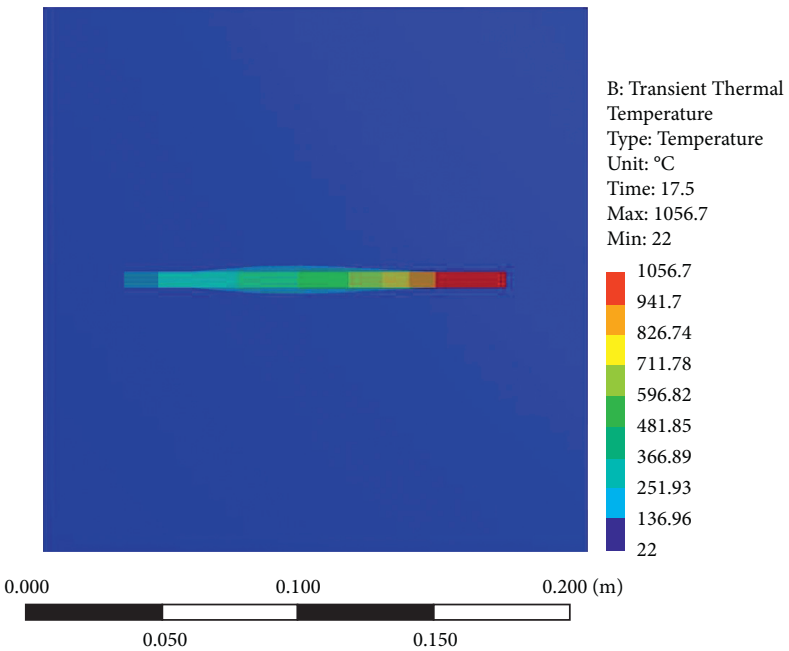

(b)

Figure 9: Continued. 


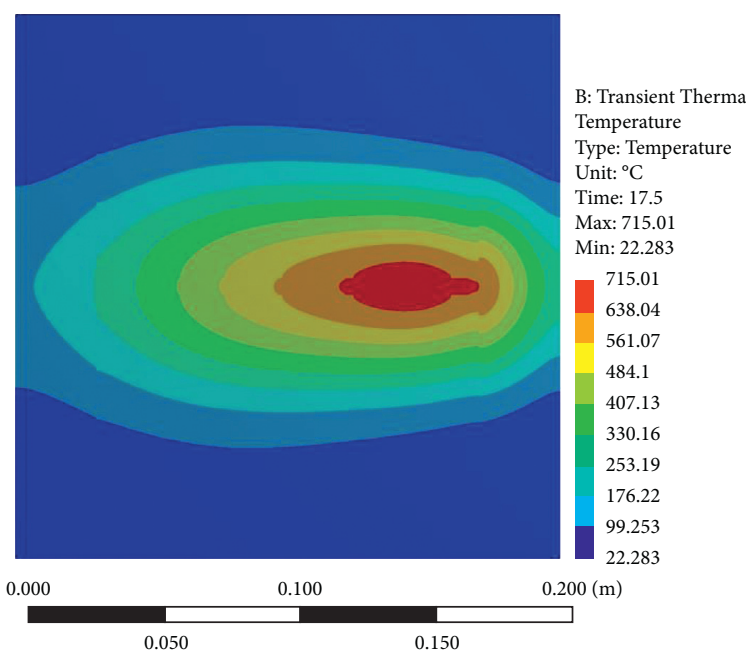

(c)

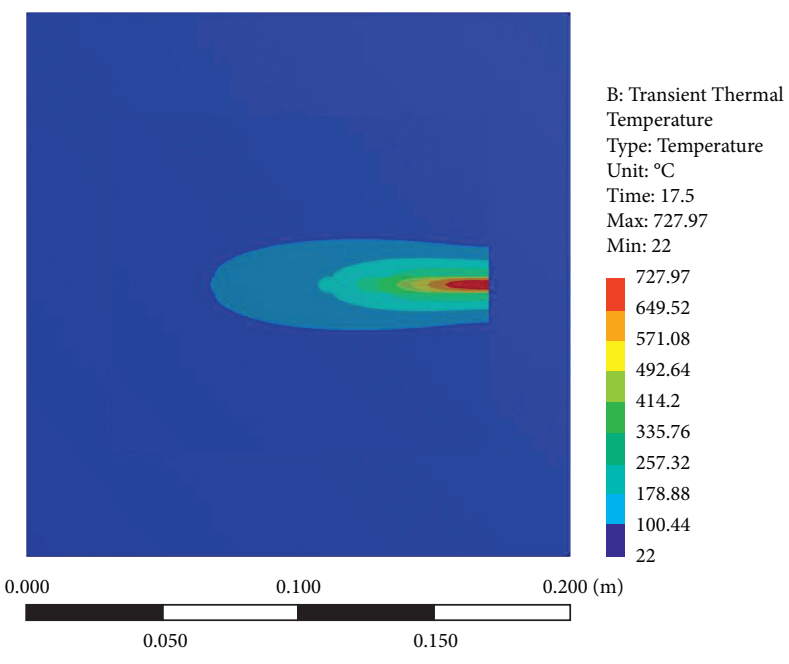

(d)

FIgURE 9: Temperature distribution of the deposition wall (a) and (b) without path restriction; (c) and (d) with the copper plates constrained path.

single-layer deposition time is $17.5 \mathrm{~s}$, the maximum temperature is $907.9^{\circ} \mathrm{C}$. The temperature field gradient distribution in the 11th layer is shown in Figure 9(b). At the end of the wall when the single-layer deposition time is $17.5 \mathrm{~s}$, the maximum temperature is $1056.7^{\circ} \mathrm{C}$. Because of heat accumulation and the slow heat-transfer rate of the deposition wall, the temperature of the tenth layer is significantly higher than that of the first layer.

For the deposition wall with the copper plates constrained path, during deposition, the heat-transfer modes of the molten pool mainly are conduction and radiation; the heat-transfer density of the molten pool is large, and the cooling rate is fast. When the deviation between the transient thermal result and actual measured temperature is within $10 \%$, then according to the transient thermal analysis, the temperature field gradient distribution of the deposition wall in the first layer is shown in Figure 9(c). At the end of the wall when the single-layer deposition time is $17.5 \mathrm{~s}$, the maximum temperature is $715.01^{\circ} \mathrm{C}$. Compared with the deposition wall without path restriction, for the deposition wall with path restriction, the maximum temperature considerably decreases, and the temperature gradient increases. The temperature field gradient distribution in the 11th layer is shown in Figure 9(d). At the end of the wall when the single-layer deposition time is $17.5 \mathrm{~s}$, the maximum temperature is $727.97^{\circ} \mathrm{C}$. Because of heat accumulation and the fast heat-transfer rate of the deposition wall, the temperature of the tenth layer is slightly higher than that of the first layer.

\subsection{Pore Flow Model}

3.3.1. Pore Nucleation and Growth. The molten pool of the deposition wall dissolves a large amount of hydrogen during additive manufacturing. During molten pool cooling, hydrogen precipitation is the essential factor for the formation of pores. The cooling rate of the molten pool is the main factor determining the number of pore nucleation per unit time [33]. During nucleation, the pores are subjected to air pressure, molten pool liquid pressure, additional pressure caused by the surface tension of the pore liquid, and electromagnetic pressure, and the internal pressure changes dynamically and is balanced with the external pressure [34]. When the nucleation radius of the pore is smaller than the critical radius, it is difficult for the pores to remain stable, and they disappear because the free energy of the gas liquid system is positively correlated with the pore radius. When the nucleation radius of the pore is smaller than the critical radius, the pores can exist stably and grow because the free energy of the gas liquid system is negatively correlated with the pore radius.

The internal pressure of pore nucleation can be expressed as follows:

$$
p=4\left(p_{a}+\rho_{L} g h\right)+\frac{\mu_{0} I \ln \left(R_{b}-R_{a}\right)}{\pi^{2} R_{b}^{2}}
$$

where $p_{a}$ is the air pressure, $\rho_{L}$ is the density of the molten pool, $g$ is the gravitational acceleration, $h$ is the pore depth, $\mu_{0}$ is the vacuum permeability, $I$ is the current, $R_{a}$ is the upper radius of the arc, and $R_{b}$ is the lower radius of the arc.

The radius of the pore nucleation can be expressed as follows:

$$
R=\frac{4\left(\sigma_{1}+\sigma_{2}\right)}{12\left(p_{a}+\rho_{L} g h\right)+3 \mu_{0} I \ln \left(R_{b}-R_{a}\right) / \pi^{2} R_{b}^{2}}
$$

where $\sigma_{1}$ is the maximum surface tension, $\sigma_{2}$ is the minimum surface tension, $p_{a}$ is the air pressure, $\rho_{L}$ is the density of the molten pool, $g$ is the acceleration of gravity, $h$ is the depth of the pore, $\mu_{0}$ is the vacuum permeability, $I$ is the current, $R_{a}$ is the upper radius of the arc, and $R_{b}$ is the lower radius of the arc. 
For the deposition wall without the path restriction, during deposition, the molten pool exhibits small heat exchange and a low cooling rate and forms pores at a slower nucleation rate in a longer cooling time.

For the deposition wall with the copper plates constrained path, during deposition, the molten pool exhibits large heat exchange and a high cooling rate and forms pores at a faster nucleation rate in a shorter cooling time.

3.3.2. Pore Movement Fusion. During additive manufacturing, the pore movement of the molten pool of the deposition wall is mainly affected by the combined action of buoyancy and additional pressure resulting from the surface tension of the pore liquid, which is used to overcome the resistance of the molten pool liquid [35]. The movement of pores can be divided into two processes; in the initial short period of time, the pores move fast because the power is greater than the resistance, and in the subsequent long period of time, the pores move at a uniform velocity because the power of the stomata is equal to the resistance [36]. The pore velocity in the $Y$ direction mainly results from the $Y$ component of the additional pressure, and that in the $Z$ direction is mainly caused by the buoyancy and $Z$ component of the additional pressure.

The $Y$ direction pore velocity can be expressed as follows:

$$
V_{Y}=\frac{2\left(\sigma_{1}-\sigma_{2}\right) \cos \theta}{9 \eta},
$$

where $\sigma_{1}$ is the maximum surface tension, $\sigma_{2}$ is the minimum surface tension, $\theta$ is the angle between the temperature gradient direction and horizontal direction, and $\eta$ is the dynamic viscosity of the molten pool.

The $Z$ direction pore velocity can be expressed as follows:

$$
V_{Z}=\frac{2\left(\left(\rho_{L}-\rho_{G}\right) g R^{2}+\left(\sigma_{1}-\sigma_{2}\right) \sin \theta\right)}{9 \eta},
$$

where $\rho_{L}$ is the density of the molten pool, $\rho_{G}$ is the density of the gas, $\sigma_{1}$ is the maximum surface tension, $\sigma_{2}$ is the minimum surface tension, $\theta$ is the angle between the temperature gradient direction and horizontal direction, and $\eta$ is the dynamic viscosity of the molten pool.

For the deposition wall without the path constraint, during deposition, the heat-transfer density of the molten pool is small, and the cooling rate is slow. The molten pool exhibits a small temperature difference in the temperature gradient direction, and the additional pressure caused by the gas liquid surface tension is small. When the pore movement reaches the equilibrium state, the liquid resistance of the molten pool is small. Therefore, the pore velocity in the $Y$ direction is small, and the velocity in the $Z$ direction is small, as shown in Figures 10(a)-10(d).

For the deposition wall with the copper plates constrained path, during deposition, the heat-transfer density of the molten pool is large, and the cooling rate is fast. The molten pool exhibits a large temperature difference in the temperature gradient direction, and the additional pressure resulting from the gas liquid surface tension is large. When the pore movement reaches the equilibrium state, the liquid resistance of the molten pool is large. Therefore, the pore velocity in the $Y$ direction is large, and the velocity in the $Z$ direction is large, as shown in Figures 10(e)-10(h).

For the deposition wall without the path constraint, during deposition, the molten pool flows downward under the action of its gravity and flows to both the sides under the action of the arc force, thus flowing downward on both the sides. Because the molten pool flows slowly in this state and the cooling rate is slower, the molten pool forms pores at a slower nucleation rate in a longer cooling time, and the pore floating rate is small. Consequently, the internal pores escape slowly during the flow of the molten pool, which accelerates the formation of hydrogen pores in the molten pool, as shown in Figures 11(a) and 11(b).

For the deposition wall with the copper plates constrained path, during deposition, the molten pool flows downward on both the sides under the action of its gravity and arc force and flows back after coming in contact with the copper plates, causing the molten pool to flow naturally to both the sides, and then, in the opposite direction. Because the molten pool flows faster in this state and the cooling rate is faster, the molten pool forms pores at a faster nucleation rate in a shorter cooling time, and the pore floating rate is high. Consequently, the internal pores escape faster during the molten pool flow, which slows down the formation of hydrogen pores inside the molten pool, as shown in Figures 11(c) and 11(d).

3.4. Microstructure Analysis. For the deposition wall without the path constraint, the metallographic structure of the cross section of the deposition wall is shown in Figures 12(a) and 12(b). During deposition, the bottom of the molten pool is in contact with the upper layer of weld, and other parts are in direct contact with the air. The molten pool naturally flows to both the sides under the action of arc pressure and gravity, and the surrounding pressure of the molten pool is the same as the atmospheric pressure. The high energy density of the molten pool and low undercooling lead to the presence of coarse columnar grains inside the deposition wall, with an average grain size of $16.2 \pm 1.4 \mu \mathrm{m}$ in the middle area of the height direction of the deposition wall, which attenuates the mechanical properties of the deposition wall.

For the deposition wall with the copper plates constrained path, the metallographic structure of the cross section of the deposition wall is shown in Figures 12 and 12(d). During deposition, the bottom and top of the molten pool are in contact with the upper layer of the weld and with the air, respectively, and other parts are in direct contact with the copper plates on both the sides. The molten pool flows naturally to both the sides and, then, flows in the opposite direction under the action of arc pressure and gravity. The surrounding pressure of the molten pool increases. Due to the lower energy density of the molten pool and higher undercooling, the refinement of coarse columnar grains occurs inside the deposition wall, with an average grain size of $13.6 \pm 1.3 \mu \mathrm{m}$ in the middle area of the height 


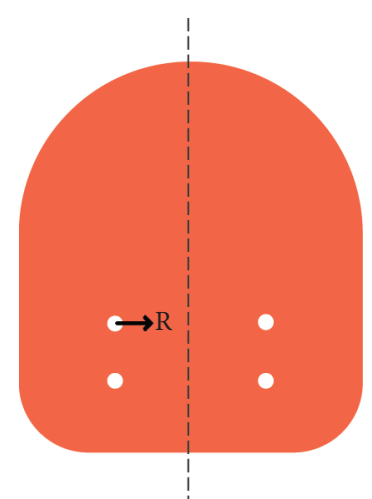

(a)

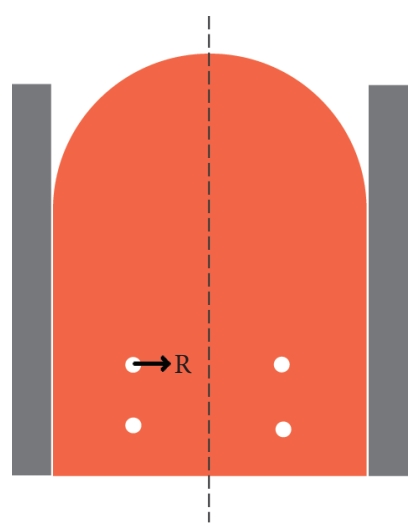

(e)

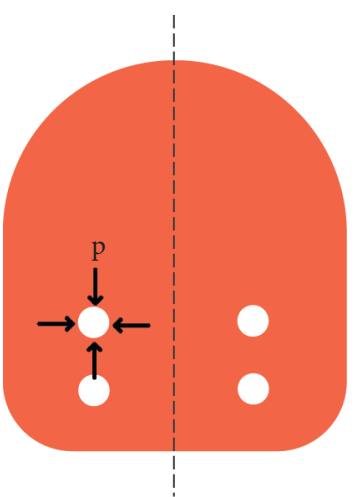

(b)

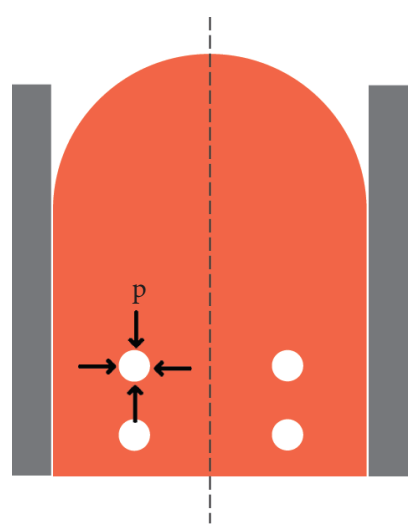

(f)

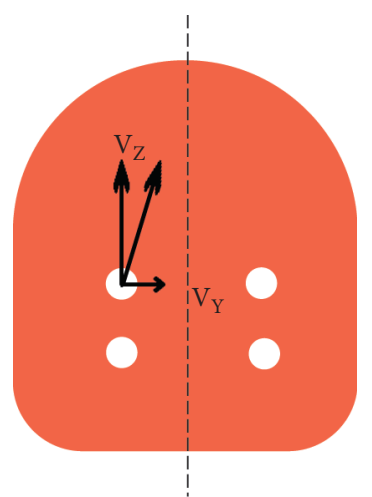

(c)

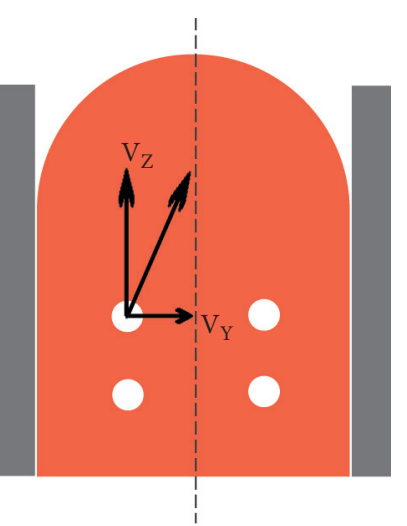

(g)

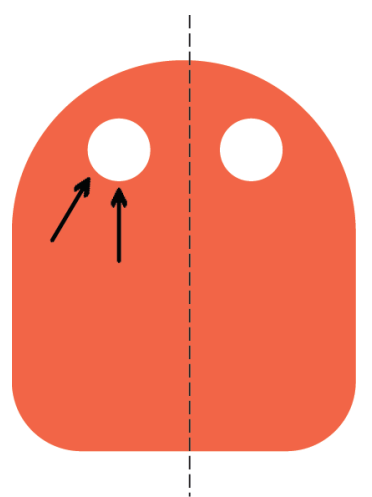

(d)

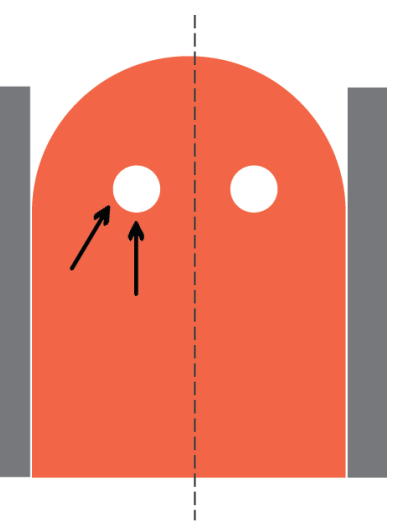

(h)

FIGURE 10: Pore nucleation growth and movement fusion of the deposition wall: (a-d) without the path constraint and (e-h) with the copper plates constrained path.

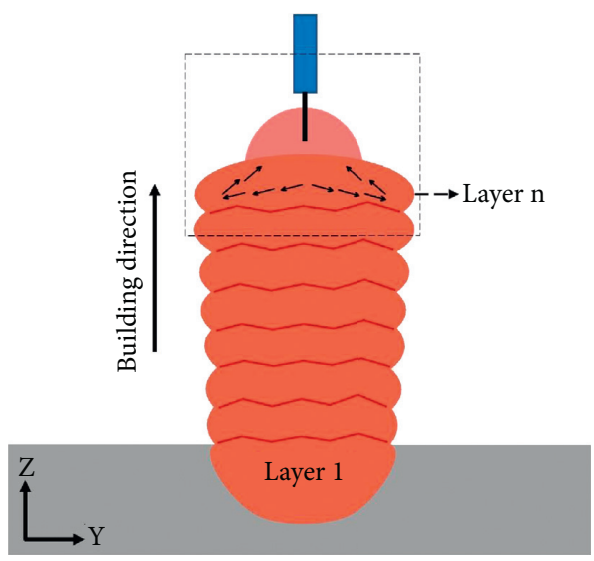

(a)

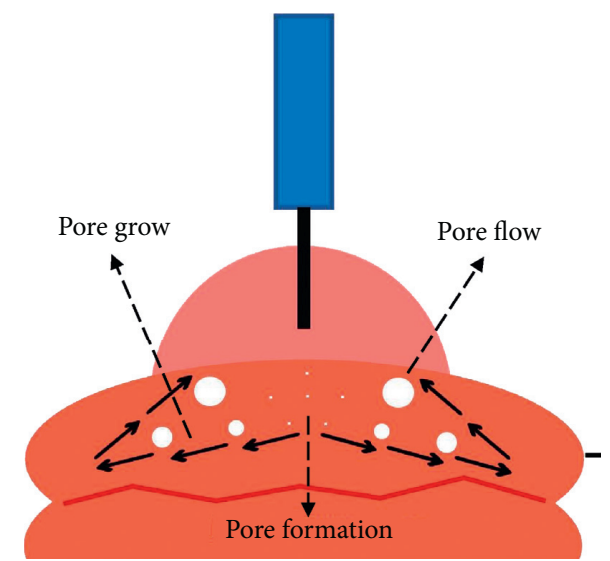

(b)

FIGURE 11: Continued. 


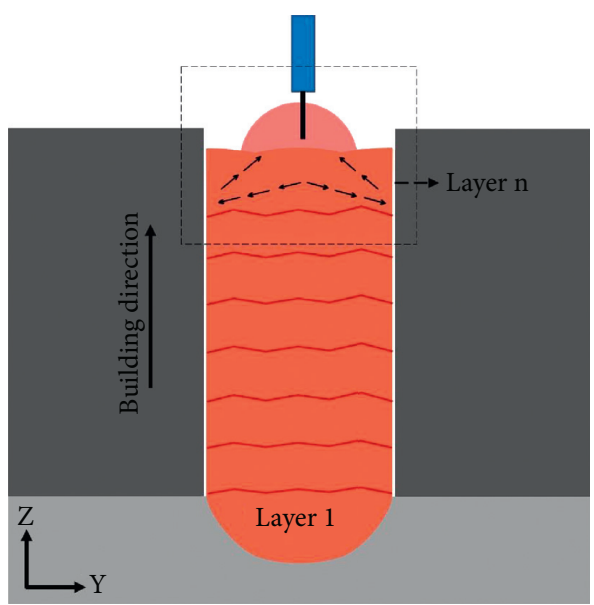

(c)

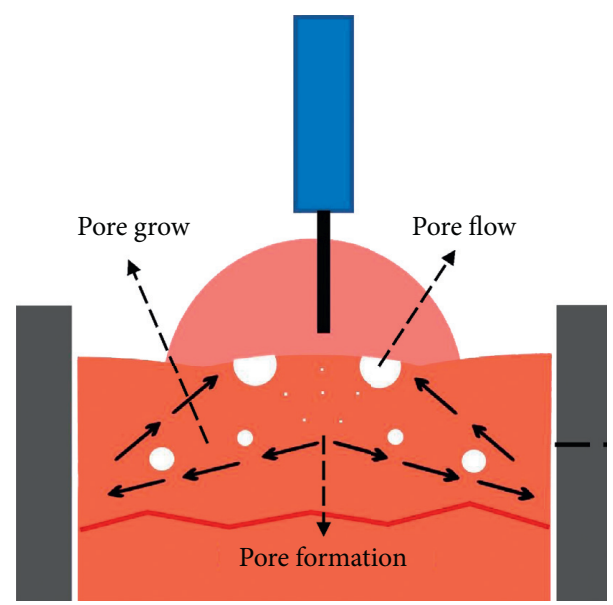

(d)

Figure 11: Pore defect generation model of the deposition wall: (a), (b) without the path constraint; (c), (d) with the copper plates constrained path.

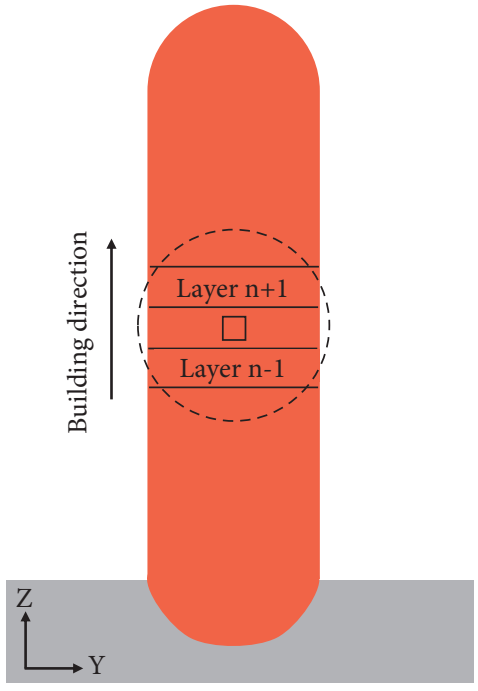

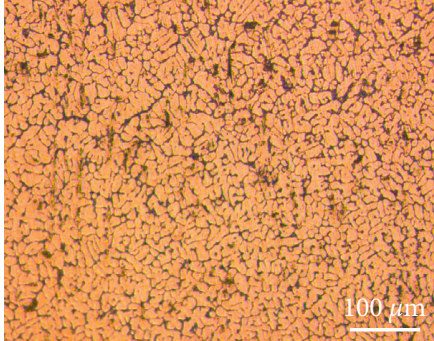

(a)

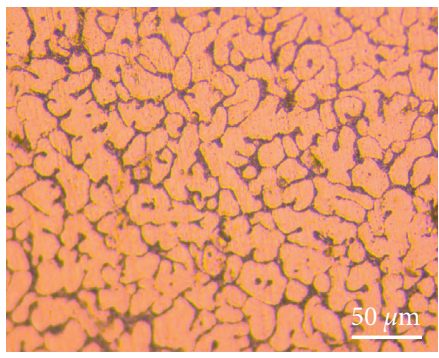

(b)

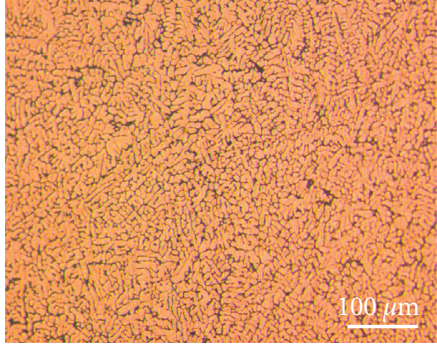

(c)

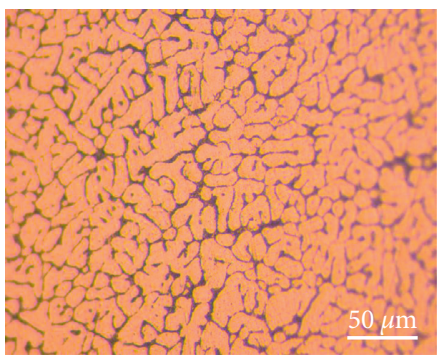

(d)

Figure 12: Metallographic structure of the cross section of the deposition wall: (a), (b) without the path constraint; (c), (d) with the copper plates constrained path.

direction of the deposition wall, which improves the mechanical properties of the deposition wall.

3.5. Mechanical Behaviour. For the deposition wall without the path constraint, the mechanical tensile strength in the deposition velocity direction and interlayer accumulation direction of the deposition wall is shown in Figure 13. The average ultimate tensile and yield strengths in the transverse section of the deposition wall are 169 and $133 \mathrm{MPa}$, respectively, and those in the longitudinal section of the deposition wall are 153 and $118 \mathrm{MPa}$, respectively. Therefore, the tensile strength of the deposition wall without the path constraint is slightly higher in the horizontal direction than in the vertical direction.

For the deposition wall with the copper plates constrained path, the mechanical tensile strength in the deposition velocity direction and interlayer accumulation direction of the deposition wall is shown in Figure 14. The average ultimate tensile and yield strengths in the transverse section of the deposition wall are 203 and $162 \mathrm{MPa}$, respectively, and those in the longitudinal section of the deposition wall are 179 and $138 \mathrm{MPa}$, respectively. Therefore, the tensile strength of the deposition wall with the copper plates constrained path improves in the horizontal and vertical directions. 


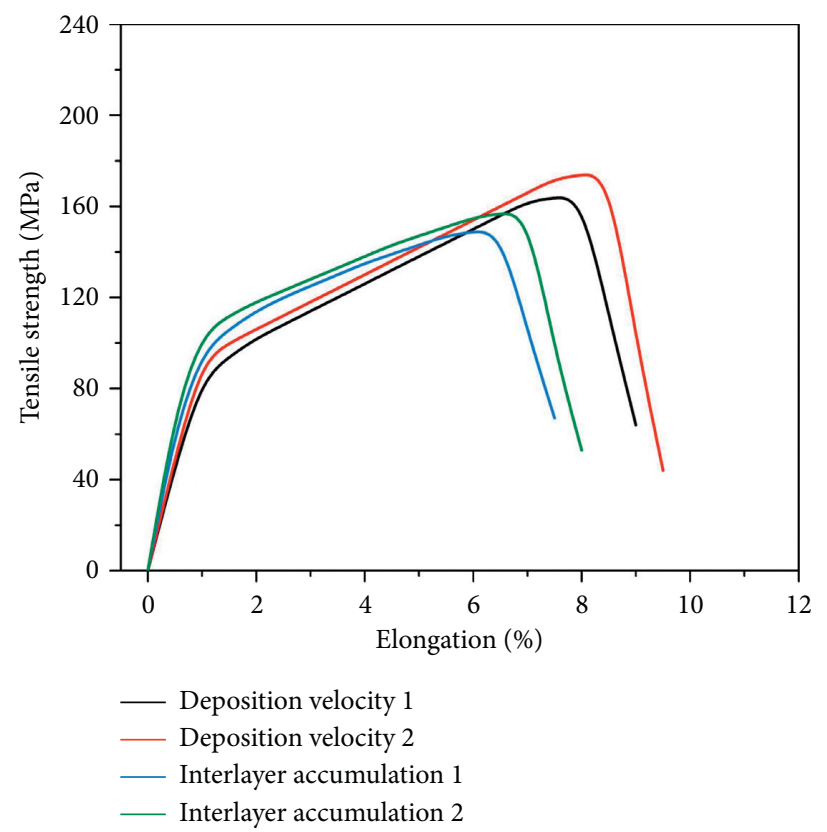

Figure 13: Tensile curves of the deposition wall in the direction of the deposition velocity and interlayer accumulation without the path constraint.

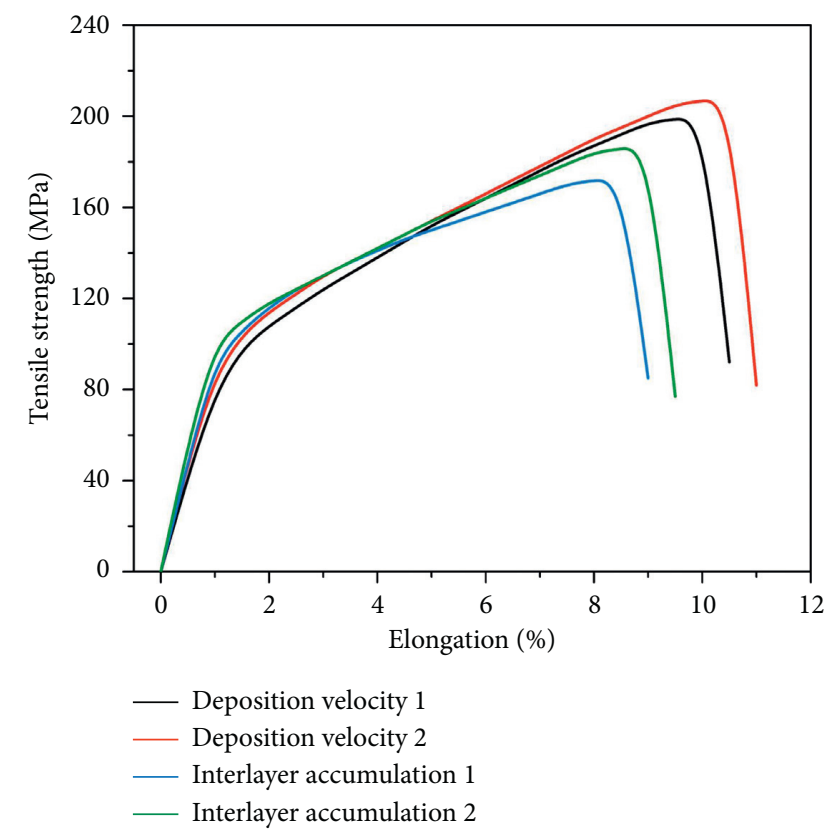

Figure 14: Tensile curves of the deposition wall in the direction of the deposition velocity and interlayer accumulation with the copper plates constrained path.

3.6. Fracture Crack Analysis. The area of the interlayer transition zone in the deposition velocity direction of the deposition wall is small, and that of the fracture cross section crack propagation zone in the deposition velocity direction is small, which confirms that the deposition wall strength is relatively higher in this direction. Additionally, because the area of the interlayer transition zone in the interlayer accumulation direction of the deposition wall is large, and that of the fracture section crack propagation zone in the interlayer accumulation direction is relatively larger, the deposition wall strength is lower in this direction. For the deposition wall without the path constraint, the tensile fracture surface and SEM image in the deposition velocity direction of the deposition wall is shown in Figures 15(a) and 15(b). Because the tensile fracture of the deposition wall is broken along the section with the smallest effective area in the tensile direction, the deposition wall fracture is distributed with large-scale pores, and the tensile strength of the deposition wall in this direction is low. Because smaller dimples are present on the fracture, the toughness of the deposition wall in this direction is poor.

The area of the interlayer transition zone in the deposition velocity direction of the deposition wall decreases, and that of the fracture cross section crack propagation zone in the deposition velocity direction decreases, which confirms that the deposition wall strength increases in this direction. Additionally, because the area of the interlayer transition zone in the interlayer accumulation direction of the deposition wall decreases, and that of the fracture section crack propagation zone in the interlayer accumulation direction decreases, the deposition wall strength decreases in this direction. For the deposition wall with the copper plates constrained path, the tensile fracture surface and SEM image in the deposition velocity direction of the deposition wall is shown in Figures 15(c) and 15(d). Compared with the deposition wall without the constraint path, the fracture of the deposition wall with the constraint path is distributed with small-scale pores, and the tensile strength of the deposition wall in this direction is high. Because larger dimples exist on the fracture, deposition wall toughness is better in this direction. 


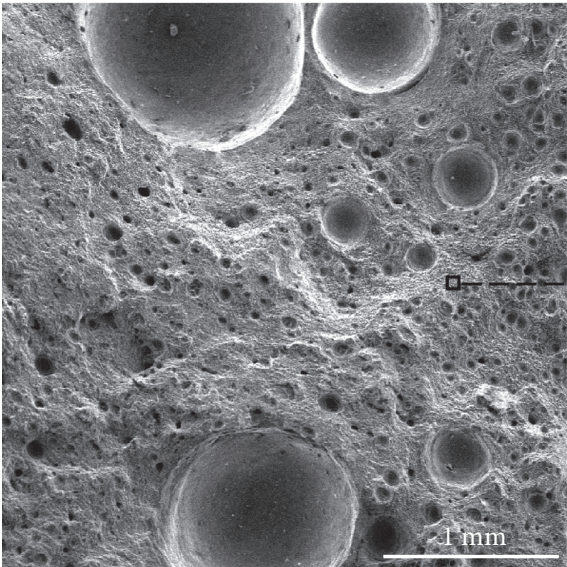

(a)

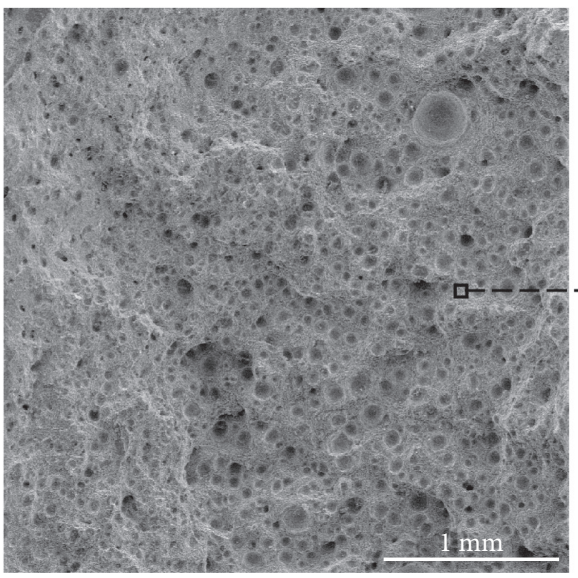

(c)

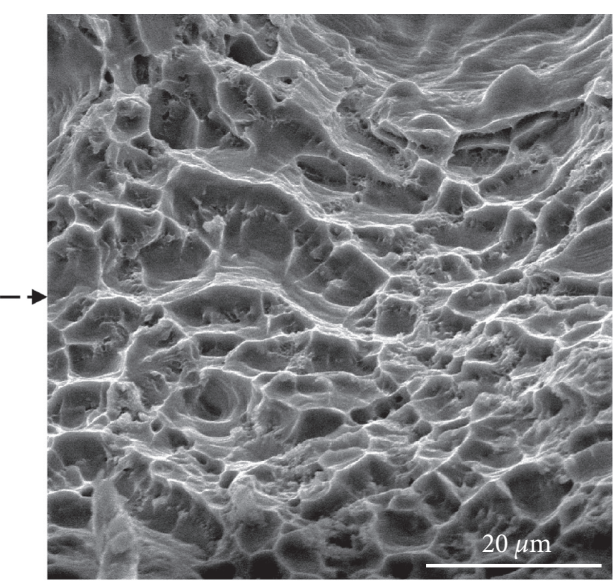

(b)

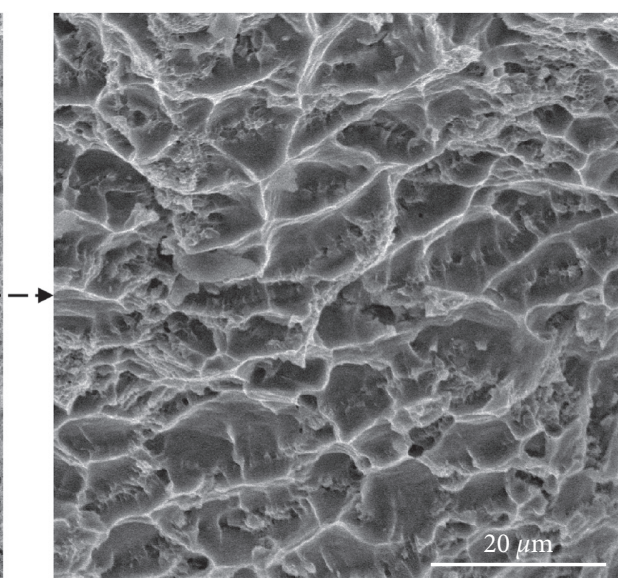

(d)

FIgURE 15: Tensile fracture surface and SEM image of the deposition wall in the deposition velocity direction: (a), (b) without the path constraint; (c), (d) with the copper plates constrained path.

\section{Conclusions}

This study developed a CMT arc additive die manufacturing process. Compared with wrought process, the mechanical properties of the arc additive die manufacturing parts are lower, but with the advantage of additive manufacturing. Compared with the common arc additive manufacturing process, the arc additive die manufacturing parts have been greatly improved in deposition accuracy and structural properties, and the following conclusions can be drawn from this study.

(1) The CMT arc additive die manufacturing process is developed. Through this manufacturing of the copper plates constrained path, the aluminium-silicon alloy achieves high-quality rapid prototyping and provides standard additive manufacturing products.

(2) The copper plates constraint path can be used to design the layer width and thickness of the deposition wall and to control reasonable side flatness and top surface fluctuations. Side flatness decreases from $11 \%$ at the highest point to $3 \%$, and top surface volatility increases from $54 \mathrm{~mm}$ at the highest point to $57 \mathrm{~mm}$.
(3) The copper plates constraint path can affect molten pool flow and material formation in the additive process, lower hydrogen pores in the deposition wall, and refine columnar grains. The porosity decreases from $2.03 \%$ to $0.93 \%$, and the average grain size decreases from $16.2 \pm 1.4$ to $13.6 \pm 1.3 \mu \mathrm{m}$.

(4) The tensile strength of the deposition wall with the copper plates constrained path is improved in the transverse and longitudinal directions. The transverse and longitudinal average ultimate tensile strength increased from 169 to $203 \mathrm{MPa}$ and 153 to $179 \mathrm{MPa}$, respectively.

\section{Data Availability}

The data used to support the findings of this study are available from the corresponding author upon request.

\section{Conflicts of Interest}

The authors declare that they have no conflicts of interest. 


\section{Acknowledgments}

This work was partially supported by the Natural Science Foundation of Shanghai (grant no. 20ZR1422600) and the Open Project of Shanghai Key Laboratory of Digital Manufacture for Thin-walled Structures (grant No. 2019-002).

\section{References}

[1] Y. Meng, J. Li, M. Gao, and X. Zeng, "Microstructure characteristics of wire arc additive manufactured $\mathrm{Ni} \mathrm{Al}$ intermetallic compounds," Journal of Manufacturing Processes, vol. 68, pp. 932-939, 2021.

[2] B. Lan, Y. Wang, Y. Liu et al., "The influence of microstructural anisotropy on the hot deformation of wire arc additive manufactured (WAAM) Inconel 718," Materials Science and Engineering A, vol. 823, Article ID 141733, 2021.

[3] Q. Miao, D. Wu, D. Chai et al., "Comparative study of microstructure evaluation and mechanical properties of 4043 aluminum alloy fabricated by wire-based additive manufacturing," Materials \& Design, vol. 186, pp. 108-205, 2020.

[4] T. Hauser, R. T. Reisch, S. Seebauer et al., "Multi-Material Wire Arc Additive Manufacturing of low and high alloyed aluminium alloys with in-situ material analysis," Journal of Manufacturing Processes, vol. 69, pp. 378-390, 2021.

[5] J. L. Gu, M. J. Gao, S. L. Yang, J. Bai, J. L. Ding, and X. W. Fang, "Pore formation and evolution in wire+arcadditively manufactured $2319 \mathrm{Al}$ alloy," Additive Manufacturing, vol. 30, pp. 100-900, 2019.

[6] C. Zhang, M. Gao, C. Chen, and X. Y. Zeng, "Spectral diagnosis of wire arc additive manufacturing of Al alloys," Additive Manufacturing, vol. 30, pp. 100-869, 2019.

[7] J. C. Wang, Y. Cui, C. M. Liu, Z. X. Li, Q. R. Wu, and D. N. Fang, "Understanding internal defects in Mo fabricated by wire arc additive manufacturing through $3 \mathrm{D}$ computed tomography," Journal of Alloys and Compounds, vol. 840, pp. 155-753, 2020.

[8] X. W. Fang, L. Zhang, G. Chen et al., "Microstructure evolution of wire-arc additively manufactured 2319 aluminum alloy with interlayer hammering," Materials Science and Engineering A, vol. 800, pp. 140-168, 2021.

[9] Y. H. Li, S. J. Wu, H. L. Li, and F. J. Cheng, "Dramatic improvement of impact toughness for the fabricating of lowcarbon steel components via submerged arc additive manufacturing," Materials Letters, vol. 283, pp. 128-780, 2021.

[10] V. T. Le and D. S. Mai, "Microstructural and mechanical characteristics of 308L stainless steel manufactured by gas metal arc welding-based additive manufacturing," Materials Letters, vol. 271, pp. 127-791, 2020.

[11] C. Wang, W. Suder, J. Ding, and S. Williams, "The effect of wire size on high deposition rate wire and plasma arc additive manufacture of Ti-6Al-4V," Journal of Materials Processing Technology, vol. 288, pp. 116-842, 2021.

[12] Z.-q. Liu, P.-1. Zhang, S.-w. Li, D. Wu, and Z.-s. Yu, "Wire and arc additive manufacturing of $4043 \mathrm{Al}$ alloy using a cold metal transfer method," International Journal of Minerals, Metallurgy and Materials, vol. 27, no. 6, pp. 783-791, 2020.

[13] V. T. Le, D. S. Mai, and Q. H. Hoang, "A study on wire and arc additive manufacturing of low-carbon steel components: process stability, microstructural and mechanical properties," Journal of the Brazilian Society of Mechanical Sciences and Engineering, vol. 42, no. 9, p. 480, 2020.
[14] Y. B. Tian, J. Q. Shen, S. S. Hu, J. Han, Q. Wang, and Y. C. Cai, "Effects of ultrasonic peening treatment layer by layer on microstructure of components fabricated by wire and arc additive manufacturing," Materials Letters, vol. 284, pp. 128-917, 2021.

[15] C. Wang, T. G. Liu, P. Zhu, Y. H. Lu, and T. Shoji, "Study on microstructure and tensile properties of $316 \mathrm{~L}$ stainless steel fabricated by CMT wire and arc additive manufacturing," Materials Science and Engineering A, vol. 796, pp. 140-006, 2020.

[16] T. Lehmann, A. Jain, Y. Jain et al., "Concurrent geometry- and material-based process identification and optimization for robotic CMT-based wire arc additive manufacturing," $M a$ terials \& Design, vol. 194, pp. 108-841, 2020.

[17] B. Dong, X. Cai, S. Lin et al., "Wire arc additive manufacturing of Al-Zn-Mg-Cu alloy: microstructures and mechanical properties," Additive Manufacturing, vol. 36, pp. 101-447, 2020.

[18] Y. Ali, P. Henckell, J. Hildebrand, J. Reimann, J. P. Bergmann, and S. Barnikol-Oettler, "Wire arc additive manufacturing of hot work tool steel with CMT process," Journal of Materials Processing Technology, vol. 269, pp. 109-116, 2019.

[19] C. Li, H. Gu, W. Wang et al., "Investigation on high-temperature mechanical properties of Al-7Si-0.6Mg alloy by wire + arc additive manufacturing," Materials Science and Technology, vol. 36, no. 14, pp. 1516-1522, 2020.

[20] V. T. Le, D. S. Mai, and Q. H. Hoang, "Effects of cooling conditions on the shape, microstructures, and material properties of SS308L thin walls built by wire arc additive manufacturing," Materials Letters, vol. 280, pp. 128-580, 2020.

[21] J. Gou, J. Shen, S. Hu, Y. Tian, and Y. Liang, "Microstructure and mechanical properties of as-built and heat-treated Ti-6Al$4 \mathrm{~V}$ alloy prepared by cold metal transfer additive manufacturing," Journal of Manufacturing Processes, vol. 42, pp. 41-50, 2019.

[22] X. Zhou, H. Zhang, G. Wang, and X. Bai, “Three-dimensional numerical simulation of arc and metal transport in arc welding based additive manufacturing," International Journal of Heat and Mass Transfer, vol. 103, pp. 521-537, 2016.

[23] P. Shukla, B. Dash, D. V. Kiran, and S. Bukkapatnam, "Arc behavior in wire arc additive manufacturing process," Procedia Manufacturing, vol. 48, pp. 725-729, 2020.

[24] Y. Fu, H. Zhang, G. Wang, and H. Wang, "Investigation of mechanical properties for hybrid deposition and microrolling of bainite steel," Journal of Materials Processing Technology, vol. 250, pp. 220-227, 2017.

[25] D. Oropeza, D. C. Hofmann, K. Williams et al., "Welding and additive manufacturing with nanoparticle-enhanced aluminum 7075 wire," Journal of Alloys and Compounds, vol. 834, pp. 154-987, 2020.

[26] S. Y. Zhou, K. Wu, G. Yang et al., "Grain-refining of wire arc additive manufactured aluminum alloy with $\mathrm{Nb}$ powder addition," Materials Research Express, vol. 8, pp. 026-520, 2021.

[27] P. Colditz, M. Graf, A. Hälsig, S. Härtel, and B. Awiszus, "Experimental investigation on the forming of additively manufactured components with regard to forming behavior and component properties," Procedia Manufacturing, vol. 47, pp. 1164-1169, 2020.

[28] J. Lizarazu, L. Göbel, S. Linne et al., "Experimental characterization and numerical analysis of additively manufactured mild steel under monotonic loading conditions," Progress in Additive Manufacturing, vol. 5, no. 3, pp. 295-304, 2020. 
[29] Y. Tian, J. Shen, S. Hu, Z. Wang, and J. Gou, "Microstructure and mechanical properties of wire and arc additive manufactured Ti-6Al-4V and AlSi5 dissimilar alloys using cold metal transfer welding," Journal of Manufacturing Processes, vol. 46, pp. 337-344, 2019.

[30] S. H. Han, Z. Z. Zhang, Z. S. Liu, H. Zhang, and D. Q. Xue, "Investigation of the microstructure and mechanical performance of bimetal components fabricated using CMTbased wire arc additive manufacturing," Materials Research Express, vol. 7, pp. 116-525, 2020.

[31] W. J. Liu, "Aluminum alloy sheet welding analysis and deformation control in CMT," School of Mechanical and Automotive Engineering Shanghai University of Engineering Science, Shanghai, China, 2020.

[32] P. Wang, Effect of Air gap at the Interface of Mould-Ingot on the Comprehensive Interfacial Heat Transfer Coefficient, University of Science and Technology Liaoning, Anshan, China, 2020.

[33] J. Du, Formation mechanism and elimination measures of pores in fusion welding of die casting magnesium alloy, College of Material Science and Engineering of Chongqing University, Chong Qing, China, 2014.

[34] Y. J. Ma, Research on Pore Sensitivity and Control Process of Aluminum alloy in Horizontal Welding, Harbin Institute of Technology, Harbin, China, 2018.

[35] Y. Q. Huang, Study on Porosity Formation Mechanisms and Processes in Welding of Galvanized Steel Sheets for a Zero-gap Lap Joint Configuration, Shanghai Jiao Tong University, Shanghai, China, 2018.

[36] Y. M. Huang, Feature Detection and Compensation Control of Porosity during AC-GTAW of Aluminum Alloys Based on Arc Spectral Data, School of Materials Science and Engineering Shanghai Jiao Tong University, Shanghai, China, 2017. 